\title{
Dietary response of the Eurasian badger, Meler meler, to a decline of its main prey in the Doñana National Park
}

\author{
J. M. Fedriani*, P. Ferreras and M. Delibes \\ Estación Biológica de Doñana, CSIC, Apto. 1056, 41080 Sevilla, Spain
}

\section{INTRODUCTION}

The Eurasian badger (Meler meler) is considered to be a harvester rather than a hunter (Lruuk, 1989), because its food usually consists of vegetables and small and easily captured animals, such as worms and insects, and it rarely captures mammals (Neal, 1986). However, in the Doñana National Park of Mediterranean Spain the badger apparently behaves as a facultative specialist in the consumption of young rabbits, Ovyctolagur cuniculur (Martın, Rodrıguez \& Delibes, 1995). In 1990, an outbreak of Rabbit Haemorrhagic Disease (RHD) caused high mortality among adult rabbits in most of the Doñana area (Villafuerte et al., 1994), although all sites of Doñana were not affected to the same extent. This situation offered the possibility of comparing the food habits of badgers in the Doñana Biological Reserve (DBR) before (data of Martın et al., 1995) and after the outbreak of RHD, while using another site where rabbit density has changed little over the last few years as a control area.

*All correspondence to: Dr J. M. Fedriani, Estación Biológica de Doñana, CSIC, Apto. I056, 41080 Sevilla, Spain:

email: Fedriani@cica.es
The study is related to the discussion about whether or not Eurasian badgers forage as food specialists (Lruuk \& Parish, I98I; Roper, 1994). The terms 'specialist' and 'generalist' can be misleading, as they are relative terms and affect different decisions (e.g. before or after to encounter a potential prey). We suggest that the Eurasian badger could be considered a specialized forager where and when it focuses its foraging on one kind of food, which would be preferred over the rest. The theory of feeding specialization requires the selected prey to be profitable and abundant and predicts an increase of dietary diversity when the selected prey becomes scarce (Futuyma \& Moreno, 1988). Hence, we test the hypothesis that the dietary diversity of badgers in Doñana is dependent on the relative biomass of rabbits in the diet, regardless of the remaining consumed foods.

\section{FTUDY AREA}

The study was carried out in the Doñana National Park $\left(37^{\circ} \mathrm{I} 0^{\prime} \mathrm{N}, 6^{\circ} 23^{\prime} \mathrm{W}\right)$. The Park is situated on the west bank of the mouth of the Guadalquivir River (southwestern Spain). The climate in Doñana is Mediterranean 


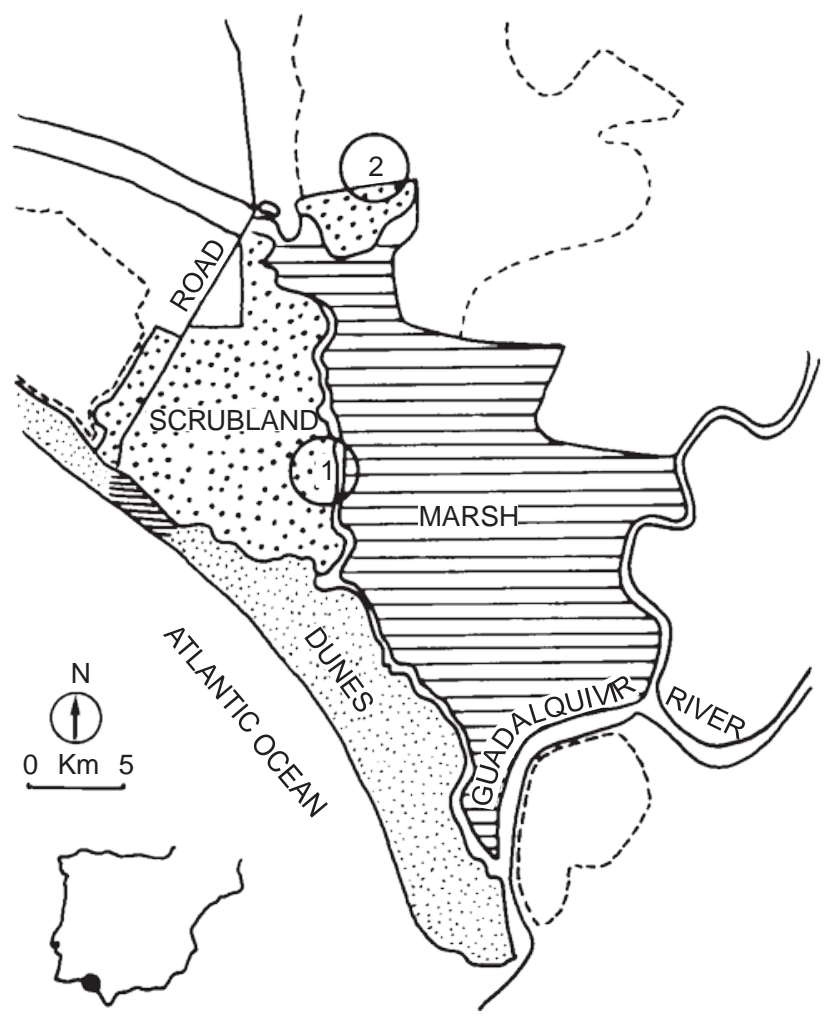

Fig. 1. Sketch map of the Doñana National Park with the location of the two study areas: I) Doñana Biological Reserve; 2) Matasgordas. Park limits are shown by a continuous line and other protected areas are indicated by a dashed line. Badgers from each area do not range in the other.

sub-humid, with an average annual rainfall of 500-600 $\mathrm{mm}$ falling mainly from November to April. Two areas were selected within the Park:

I. Doñana Biological Reserve (DBR): described by Martın et al. (1995) and located in the centre of the Park (Fig. I). Three main biotopes were distinguished within this area: marsh, dunes and scrubland. The scrubland was dominated by Halimium halimifolium shrubs with scattered Quevcur rubev trees, while tcivpur spp. were dominant in the marsh. As in the study by Martin et al. (1995), we collected faeces in DBR in the ecotone scrubland-marsh. The annual average density of adult rabbits in this area during 1977-78 was not directly measured but assumed to be about 7-9 individuals/ha (Lufner, 1986). After RHD, annual average rabbit abundance in the DBR has remained consistently at levels five or six times below those registered before the disease outbreak (Villafuerte \& Moreno, In press).

2. Matasgordas (MG): situated also in the ecotone scrubland-marsh but $15 \mathrm{~km}$ north from DBR (Fig. I). The dominant shrub in this area was Pirtacea lentircur, and Quevcur rubev and Fraxinus sp. trees were abundant. Though it is situated only $15 \mathrm{~km}$ north from the DBR, for unknown reasons the incidence of RHD in this area has been low and average rabbit density has been estimated as II-I8 ind/ha (Palomares et al., 1995).

\section{METHODF}

We analysed 145 faeces collected in the DBR in the 2 years following the first known outbreak of RHD (i.e. the period 1990-1992) and 209 faeces collected in MG during 1992-1994. All samples were well distributed over the year. For purposes of comparison, we used the 265 latrine contents collected in DBR before RHD and reported by Martın et al. (1995). Because the availability of young rabbits is higher from December to May (Delibes \& Calderón, 1979; Rogers, Arthur \& Soriguer, 1994), we considered separately the diets of the so-called wet (Dec.-May) and a dry (June-Nov.) periods at each area.

Contents of faeces were determined using methods described by Reynolds \& Aebischer (199l). We excluded infrequent prey (Roper, 1994) that represented less than $0.5 \%$ of the ingested biomass. Importance in the diet of each prey category was quantified by 2 methods: I) frequency of occurrence $=$ number of occurrences of each prey type $\times 100 /$ number of faecal samples; 2) estimate of ingested fresh biomass by using correction factors (Lockie, 1959); the estimated ingested biomass = fraction of each prey type (estimated visually) $x$ dry weight of the faecal sample $\times$ correction factor $\times 100 / Z$ (dry weight of remains $\times$ correction factors). We used the same correction factors as Martın et al. (1995).

Differences in occurrence of particular prey categories among pairs of compared diets were evaluated by chisquare analysis of contingency tables with the Bonferroni confidence intervals (Rice, 1989). Diet diversity was calculated using the Levins Index and diet similarities were calculated using the Renkonen's Index (Lrebs, 1989). Spearman rank correlation coefficients were used to relate trophic diversity and the importance of different prey categories.

\section{REFULTF}

Young rabbits were the main prey item consumed by badgers in Matasgordas, during both the wet and the dry period (Table I). Although frequencies of occurrence of rabbits differed between Matasgordas and the Doñana Biological Reserve before RHD (at least for the wet period; Table I), the ingested biomass of rabbits was consistently high in both yearly periods and both areas (always above 55\%; Table I). According to the Renkonen indices, dietary similarities were high between MG and DBR before RHD (8I.3\% and $75.6 \%$ in wet and dry season, respectively), low between DBR before and DBR after RHD (60.2\% and 46.2\%) and intermediate between MG and DBR after RHD (64.0\% and 62.35\%).

Regarding other food categories, some statistical differences appeared when comparing frequencies of occurrence, probably related to local differences in availability. For example, fruit consumption was higher in MG with regard to DBR before RHD during both seasons (wet: $z^{2}=65.3$, d.f. $=$ I, $P<0.001$; dry: $z^{2}=24.0$, d.f. $=\mathbf{I}, \mathrm{P}<0.00 \mathrm{I})$ and with regard to $\mathrm{DBR}$ after $\mathrm{RHD}$ during the wet season $\left(z^{2}=34.4\right.$, d.f. $=\mathbf{I}$; $\left.P<0.001\right)$, 
Table 1. Frequency of occurrence and percentage of biomass of each prey type in each study area and period, and diversity (Levins Index values). In brackets sample size. MG = Matasgordas. DBR = Doñana Biological Reserve. RHD = Rabbit Haemorrhagic Disease

\begin{tabular}{|c|c|c|c|c|c|c|}
\hline & \multicolumn{2}{|c|}{ MG } & \multicolumn{2}{|c|}{ DBR after RHD } & \multicolumn{2}{|c|}{ DBR before RHD } \\
\hline & $\%$ Occurrence & $\%$ Biomass & $\%$ Occurrence & $\%$ Biomass & $\%$ Occurrence & \% Biomass \\
\hline \multicolumn{7}{|l|}{ Wet zeazon } \\
\hline & $(n=108)$ & & $(n=77)$ & & $(n=162)$ & \\
\hline Lagomorphs & 39.8 & 62.1 & 20.8 & 40.9 & 67.3 & 80.9 \\
\hline Small mammals & 10.2 & 3.1 & 6.5 & 3.5 & 9.9 & 0.9 \\
\hline Birds & 0.9 & 0.1 & 9.1 & 12.4 & 1.8 & 0.0 \\
\hline Reptiles & 7.4 & 0.6 & 3.9 & 0.3 & 9.9 & 0.4 \\
\hline Amphibians & 19.4 & 4.2 & 7.8 & I.I & 9.3 & 1.7 \\
\hline Insects & 96.3 & 17.4 & 89.6 & 40.4 & 81.5 & 16.0 \\
\hline Fruits & 38.0 & 12.0 & 1.3 & 0.7 & 1.2 & 0.0 \\
\hline Levins Index & 2.32 & 2.89 & 1.47 & & & \\
\hline \multicolumn{7}{|l|}{ Dry zeazon } \\
\hline Lagomorphs & 37.6 & 55.6 & 8.8 & 21.6 & 56.3 & 61.1 \\
\hline Small mammals & 4.9 & 3.1 & 0.0 & 0.0 & 4.8 & 0.8 \\
\hline Birds & 4.0 & 1.3 & 4.4 & 11.5 & 4.8 & 1.7 \\
\hline Reptiles & 11.9 & 3.4 & 7.3 & 7.9 & 16.5 & 10.3 \\
\hline Amphibians & 8.9 & 1.3 & 5.9 & 0.5 & 26.2 & 12.0 \\
\hline Insects & 86.1 & II. 2 & 97.1 & 13.8 & 76.7 & 12.0 \\
\hline Fruits & 53.5 & 23.8 & 32.3 & 42.5 & 20.4 & 2.0 \\
\hline Levins Index & & 2.65 & & 3.69 & & 2.45 \\
\hline
\end{tabular}

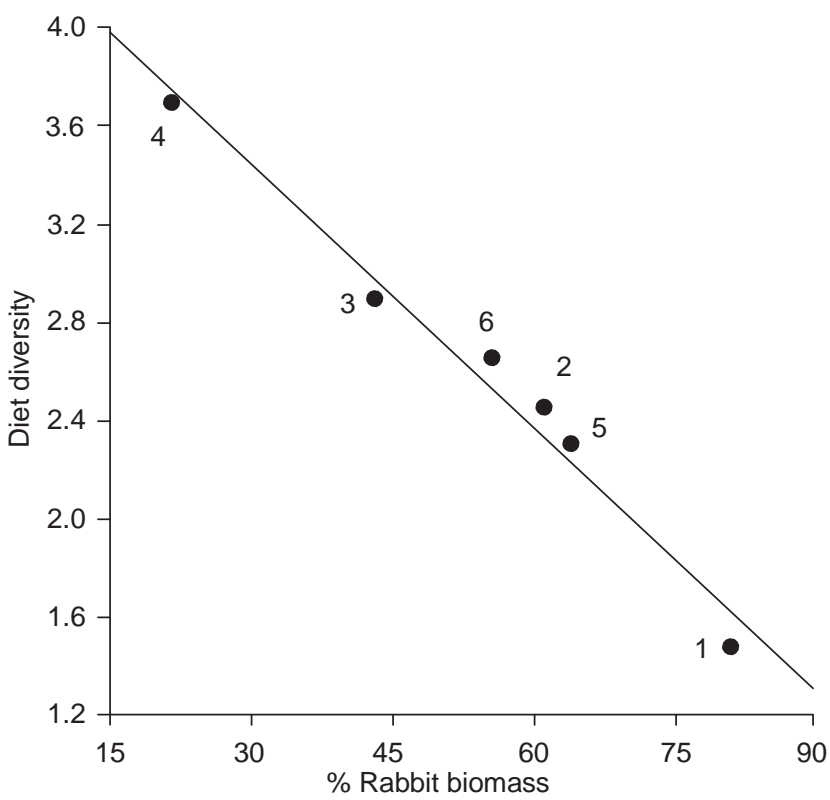

Fig. 2. Correlation between dietary diversity (as Levins Index) and the percentage of ingested biomass of rabbit. $\mathbf{I}=$ Doñana Biological Reserve (DBR) before rabbit haemorrhagic disease (RHD) in wet season. $2=$ DBR before RHD in dry season. 3 $=\mathrm{DBR}$ after RHD in wet season. $4=\mathrm{DBR}$ after RHD in dry season. $5=$ MG in wet season. $6=$ MG in dry season.

while no significant differences were detected with regard to DBR after RHD during the dry season.

Ingested young rabbit biomass declined about 50\% during the wet period and 33\% during the dry period in the DBR after the outbreak of RHD (Table I). In both wet and dry periods, frequencies of occurrence of rabbit varied significantly with regard to DBR before RHD and to $\mathrm{MG}(\mathrm{P}<0.00 \mathrm{l})$. Nevertheless, young rabbits continued to be an important food item, particularly during the wet season (4l\%). Young rabbits were not replaced by a single prey category in the badger's diet in any season. Alternative foods included insects and birds in the wet season and fruit, insects and birds in the dry season (Table I). Dietary diversity almost doubled during the wet season and increased 1.5 times during the dry season following the RHD outbreak (Table I).

The percentage of rabbit biomass in the diet was negatively correlated with food diversity $\left(r_{s}=-I, n=6\right.$, $\mathrm{P}<0.00$; Fig. 2), suggesting that dietary diversity was related to the availability of young rabbits and relatively independent of the availability of food types other than rabbits. There was a significant positive correlation between diet diversity and percentage of bird biomass $(P<0.05)$, suggesting that birds were a typical complementary food.

\section{DIFCUFFION}

Given the remarkable geographical, seasonal and individual variations detected in Eurasian badger diets (e.g. Lüps \& Wandeler, 1993), some authors support the traditional view that the species is an opportunistic food generalist (e.g. Roper, 1994; Roper \& Mickevicius, 1995). Other authors describe the foraging behaviour of some Eurasian badger populations as being more characteristic of specialized feeders, relying locally on single resources, such as earthworms (Lruuk \& Parish, 198I), some fruit (Lruuk \& de Lock, I98I), insects and fruit (Pigozzi, I99I) or young rabbits (Martın et al., I995). 
The more simplistic interpretation of our results suggests that badgers in the Doñana area are opportunistic feeders, because they changed their diet in DBR after rabbits became scarce. However, such a change in diet diversity of facultative specialists when the encounter rate with preferred prey declines is predicted by most theoretical models of food specialization (e.g. Stephens \& Lrebs, 1986). In fact, one of the axioms of classical foraging theory is that dietary diversity of specialists is governed by encounter rate with the more profitable prey, regardless of abundance of other food resources (Futuyma \& Moreno, 1988). In our case, availability of rabbits seems to be the key to badger's diet diversity (Fig. 2). Despite the change in rabbit numbers, there was no possibility of a change in the availability of rabbits per individual badger, if the numbers of badgers had also decreased. However, we were unable to detect a shortterm numerical response of predators, including badgers, to the rabbit decline after RHD (Delibes et al., 1992).

Our results suggest that, only when rabbit became scarce, in DBR after RHD, was the diet diversity increased. We assume that the seasonal availability of insects and fruit in DBR was not noticeably modified by the RHD outbreak; nevertheless, these seasonal changes in secondary prey abundance, very conspicuous in the DBR badger diet after RHD (Table I), were not reflected in the diets where and when rabbits were abundant.

According to Brown \& Morgan (1995), the forager's diet results from a two-step decision process: select where to seek food, and once there, select what to eat. Probably Doñ ana badgers could be considered selective predators because they start searching for young rabbits by foraging on good rabbit breeding grounds, independently of the abundance of alternative foods which could be eaten in an opportunistic way, as they were found while searching for rabbits (Martın et al., 1995; Rodriguez, Martın \& Delibes, 1996).

A question remains as to why Eurasian badgers apparently behave as a selective predator in different places. Obviously, they cannot be considered morphological, physiological or even behavioural specialists in the evolutionary sense of Futuyma \& Moreno (1988). Paradoxically, it seems they are opportunistic to a point which enables them to adapt their feeding behaviour to act locally as true specialists, on such different food resources as earthworms or rabbits.

The described dietary response of the Doñana badgers to a decline in preferred prey was similar to that of some Scottish badger populations when earthworms became scarce (Lruuk, 1989). In the long term, we could expect a change in the Doñana badger population size, although we hope the species will not disappear, as happened in the Ardnish study area of Lruuk (1989) following a change in land use which gave rise to a decrease in the availability of earthworms.

\section{Asknowledgmentz}

We are indebted to Rafael Laffitte for his help collecting faeces and to Cristina Zapata for her help analysing them. We thank Xim Cerdá, Hans Lruuk, Tim Roper, Linda M. Ilse, Alejandro Rodriguez, Eloy Revilla and Francisco Palomares for constructive comments on draft manuscripts. Claudia Leller kindly revised the English version. This study was supported by Dirección General de Investigación Cientifica y Técnica (projects PB-87/0405 and PB-94/0480) and the Senior author (JMF) by a predoctoral grant from the Ministerio de Educación y Ciencias of Spain.

\section{REFERENCEF}

Brown, J. S. \& Morgan, R. A. (1995). Effects of foraging behavior and spatial scale on diet selectivity: a test with fox squirrels. Oikor 74: I22-136.

Delibes, M. \& Calderón, J. (1979). Datos sobre la reproducción del conejo, Ovyctolagur cuniculur (L.), en Doñana, S.O. de España, durante un año seco. Doñana Acta Vevt. 6: 91-99.

Delibes, M., Ferreras, P., Travaini, A. \& Laffitte, R. (1992). Erolución de lar poblacioner de cavnrovor del Pavque Nacional de Doñana. Technical report ICONA-CSIC.

Futuyma, D. J. \& Moreno, G. (1988). The evolution of ecological specialization. Annu. Rer. Ecol. tyrt. 19: 207-233.

Lrebs, C. J. (1989). Ecological methodology. New York: Harper \& Row.

Lruuk, H. (1989). The rocial badgev. Oxford: Oxford University Press.

Lruuk, H. \& de Lock, L. (198I). Food and habitat of badgers (Meler meler L.) on Monte Baldo, northern Italy. Z. täugetievkd. 46: 295-30l.

Lruuk, H. \& Parish, T. (198I). Feeding specialization of the European badger Meler meler in Scotland. J. Appl. Ecol. 50: 773-788.

Lufner, M. B. (1986). Tamaño, actiridad, denridad velatira y pvefevencia de hábitat de lor pequeñor y medianor mamfevor de Doñana, como factover condicionanter de ru tara de pvedación. $\mathrm{PhD}$ thesis, Autó noma University, Madrid.

Lockie, J. D. (1959). The estimation of the food of foxes. J. Wildl. Manage. 23: 224-227.

Lüps, P. \& Wandeler, A. I. (1993). Dachs (Meler meler). In Handbuch dev täugetieve Euvopar. 5. Carnivora. Stubbe \& Lrapp (Eds). Wiesbaden: Aula-Verlag.

Martın, R., Rodrıguez, A. \& Delibes, M. (1995). Local feeding specialization by badgers (Meler meler) in a mediterranean environment. Oecologia 101: 45-50.

Neal, E. (1986). The natuval hirtovy of badgevr. London: Croom Helm.

Palomares, F., Gaona, P, Ferreras, P. \& Delibes, M. (1995). Positive effects on game species of top predators by controlling smaller predator populations: an example with Lynx, mongoose, and rabbits. Conr. Biol. 9: 295-305.

Pigozzi, G. (I99I). The diet of the European badger in a Mediterranean coastal area. Acta Theviol. 36: 293-306.

Reynolds, J. C. \& Aebischer, N. (199I). Comparison and quantification of carnivore diet by faecal analysis: a critique, with recommendations, based on a study of the fox Vulper rulper. Mammal. Rer. 12: 97-122.

Rice, W. R. (1989). Analyzing tables of statistical tests. Erolution 43: 223-225.

Rodrıguez, A., Martın, R. \& Delibes, M. (1996). Space use and activity in a mediterranean population of badgers Meler meler. Acta Theviol. 41: 59-72.

Rogers, P. M., Arthur, C. P. \& Soriguer, R. C. (1994). The rabbit in continental Europe. In The Euvopean vabbit. The hirtovy and biology of a ruccerrful colonizev: 22-63. Thompson, H. V. \& Ling, C. M. (Eds). Oxford: Oxford University Press. 
Roper, T. J. (1994). The European badger Meler meler: food specialist or generalist?. J. Zool. (Lond.) 234: 437-452.

Roper, T. J. \& Mickevicius, E. (1995). Badger Meler meler diet: a review of literature from the former Soviet Union. Mammal Rer. 25: II7-129.

Stephens, D. W. \& Lrebs, J. R. (1986). Fovaging theovy. New Jersey: Princeton University Press.
Villafuerte, R., Calvete, C., Gortázar, C. \& Moreno, S. (1994). First epizootic of rabbit haemorrhagic disease in free living populations of Ovyctolagur cuniculur at Doñana National Park, Spain. J. Wildl. Dir. 30: 176-179.

Villafuerte, R. \& Moreno, S. (In press). Variación de la abundancia de conejos en dos hábitats distintos de la Reserva Biológica de Doñana (suroeste de la Pennsula Ibérica). Doñana Acta Vevt.

J. Zool., Lond. (I998) 245, 218-222

Diet of two species of mink in Estonia: displacement of Murtela lutveola by M. riron

\author{
T. Maran',3, H. Lruuk ${ }^{2 *}$, D. W. Macdonald ${ }^{3}$ \& M. Polma' \\ 'Tallinn Zoo, Tallinn, Estonia \\ ${ }^{2}$ Institute of Terrestrial Ecology, Banchory AB3I 4BY, Scotland \\ ${ }^{3}$ Wildlife Conservation Research Unit, Department of Zoology, Oxford OXI 3PS, U.L.
}

\begin{abstract}
Abztrast
During a period in the 1980s when both European mink Murtela lutveola and American mink M. riron were present in Estonia, their food was significantly different. European mink ate a greater proportion of fish and crustaceans, whereas American mink took relatively more mammals and frogs. This was probably related to a difference in habitat selection. After the disappearance of the European mink, the diet of the American mink in our main study area was similar to that of the European in the same area previously. Two alternative hypotheses are presented for the mechanisms which led to the replacement of European mink by the American species: (i) the two species have a different niche, and the American mink could replace the European mink after the latter had disappeared for unrelated reasons, or (ii) the American mink aggressively ousted the European mink, a process starting in the American mink's preferred habitat (slow flowing rivers). At present there are insufficient data to reject either of these scenarios.
\end{abstract}

Łey wordz: diet, mink, habitat, competition, extinction

\section{INTRODUCTION}

The decline of the European mink Murtela lutveola in the second half of the 20th century has been catastrophic, and now this species is at risk of being the next mammalian extinction in Europe. Amongst the hypotheses that seek to explain the decline, several concern the relationship between the endemic European mink and the introduced American mink M. riron. In particular, questions arise of evidence of competition for food, niche overlap and displacement, between the species. One way to test such a competition hypothesis is to make use of the natural experiment provided by the disappearance of the European mink, and compare the American mink's diet before and after.

In this paper, we provide data on the food of the European mink and the American mink over a large area of Estonia. After the European mink disappeared from the country, data were collected on diet of the American mink along one of the rivers, and they were

*All correspondence to: $\mathrm{Dr} \mathrm{H}$. Lruuk, Institute of Terrestrial Ecology, Banchory AB3I 4BY, Scotland compared with the diet of European mink during its occupancy of the same river in the preceding period.

The course of the decline since the early 1970s, and final disappearance of the European mink from Estonia after 1992, have been well documented (Maran, 1991; Maran \& Henttonen, 1995). It parallels the rapid decline of the species elsewhere in Eastern Europe, in contrast to its performance in Spain where numbers are steady or increasing (Bárta, I956; Szunyoghy, I974; Schreiber et al., 1989; Romanowski, 1990; Palomares, 199l). Despite our rather detailed knowledge of the Eastern European decline and enumeration of possible causes (Maran \& Henttonen, 1995; Maran et al., In press), no satisfactory single explanation has been put forward, and no simple solution for the conservation of European mink is yet available.

The demise of European mink in Estonia coincided with the establishment there, in the early 1970s, of the American mink (Maran, 199l), although the European mink had been in long-term decline even before the arrival of its exotic congener. One of the possible, final causes of the European mink's disappearance, therefore, could be simple competition for resources with a 